\title{
DESENVOLVIMENTO E TESTE DE UMA ESCALA PARA MENSURAÇÃO DAS CARACTERÍSTICAS QUE INCENTIVAM A ADOÇÃO DE NOVOS PRODUTOS: UM ESTUDO SOBRE OS CARROS BI-COMBUSTÍVEIS
}

\author{
MOURA, Luiz Rodrigo Cunha Moura ${ }^{1}$ \\ TORRES, Ednardi Pereira ${ }^{2}$ \\ CUNHA, Nina Rosa Silveira ${ }^{3}$ \\ MOURA, Luiz Eduardo Leite de ${ }^{4}$ \\ CAIXETA, Lilian Virgina ${ }^{5}$
}

\begin{abstract}
RESUMO: Apesar do seu lançamento recente, nos últimos anos os automóveis bi-combustíveis alcançaram grande sucesso no mercado brasileiro. O objetivo é identificar quais são os principais atributos que são valorizados pelos consumidores. Também, criou-se uma escala para mensurar a percepção dos consumidores acerca das características - vantagem relativa, complexidade, divisibilidade, compatibilidade e comunicabilidade - que incentivam a aceitação dos automóveis bi-combustíveis, bem como, validou-se a escala e verificou-se por meio de uma análise fatorial, se os fatores que incentivam a adoção dos automóveis bi-combustíveis podem ser extraídos a partir dessa escala. A pesquisa foi dividida em duas etapas. Na primeira foram realizadas dez entrevistas com profissionais do setor de comercialização de veículos e com consumidores. Os resultados foram utilizados para a confecção dos questionários. Em seguida foi realizado um pré-teste para possíveis correções e cálculo da amostra. Obteve-se 261 questionários válidos. A escala apresentou uma boa validade interna e os atributos mais valorizados pelos consumidores são a economia, praticidade e modernidade do produto. Os resultados da análise fatorial foram promissores. A partir de quatro fatores extraídos, conseguiu-se representar alguns dos fatores descritos na teoria.
\end{abstract}

Palavras-Chave: Comportamento do consumidor. Adoção de novos produtos. Desenvolvimento de escala.

SUMMARY: Although its recent launching, the automobiles bi-fuels had in recent years reached great success in the Brazilian market. The objective is to identify which is the main attributes that are valued by the consumers. Also, a scale was created to measure the perception of the consumers concerning the characteristics - relative advantage, complexity, divisibility, compatibility and communicability - that they stimulate the acceptance of the automobiles bi-fuels, as well as, was become valid it scales it and it was verified by means of an factorial analysis, if the factors that stimulate the adoption of the automobiles bi-fuels can be extracted from this scale. The research was divided in two stages. In the first one ten interviews with professionals of the sector of commercialization of vehicles and with consumers had been carried through. The results had been used for the confection of the questionnaires. After that it was carried through a daily pay-test for possible corrections and calculation of the sample. One got 261 valid questionnaires. The scale presented a good internal validity and the attributes more valued by the consumers are the economy, praticidade and modernity of the product. The results of the factorial analysis had been promising. From four extracted factors, it was obtained to represent some of the described factors in the theory.

Keywords: Consumer behavior. Adoption of new products. Development of scale.

\footnotetext{
${ }^{1}$ Bacharel em Informática pela Universidade Federal de Viçosa-MG. Especialista em Tecnologia da Informação e Gestão Empresarial pela PUC - MINAS. Mestre em Administração pela UFMG. Doutor em Administração pela UFMG. Professor Adjunto do Centro Universitário UNA.

2 Bacharel em Administração - Centro Universitário UNA. Especialista em Gestão Empresarial pelo Centro Universitário UNA.

3 Bacharel em Direito pela Faculdade de Itauna - MG. Mestra em Administração pela UFMG. Doutora em Economia Rural pela UFV. Professora Associada da Universidade Federal de Viçosa - MG.

${ }^{4}$ Bacharel em Direito pela Faculdade de Itaúna - MG. Bacharel em Administração pelo Centro Unversitário UNA - MG. Mestre em Administração pelo FEAD-MG. Professor da Universidade Presidente Antônio Carlos Campus Ponte Nova - MG.

${ }^{5}$ Tecnóloga em Processamento de Dados pelo Centro Universitário UNA. Especialista em Marketing pelo FEADMG.
} 


\section{INTRODUÇÃO}

\section{CONTEXTUALIZAÇÃO}

Atualmente, os carros bi-combustíveis que utilizam simultaneamente o álcool e gasolina como combustíveis são um sucesso de vendas. Já abocanharam uma grande fatia do market share dos carros novos vendidos hoje no Brasil. Dos modelos fabricados pela Fiat, $80 \%$ dos automóveis apresentam esse tipo de motorização e em dois anos, $100 \%$ dos carros fabricados pela Volkswagen serão bi-combustíveis (AGÊNCIA AUTO PRESS, 2005). Os dados mais recentes, referentes ao ano de 2010 (FENABRAVE, 2010) indicam que os automóveis bi-combustíveis representam $94,5 \%$ de todos os emplacamentos no país, sendo que os movidos somente à gasolina representaram 5,3\% do total. Os automóveis movidos a gás, gasolina e etanol atingiram $0,2 \%$ do total do mercado.

Eles foram lançados em março de 2003, quando a Volkswagen lançou o seu modelo Gol Total Flex. Três dias depois, a FIAT fez o mesmo e lançou o mesmo sistema bi-combustível. (FELDMAN, 2003).

O processo de adoção deste produto pelo consumidor brasileiro foi muito rápido. Um ano após o lançamento do primeiro modelo bi-combustível, esse tipo de produto já detinha $13,5 \%$ da venda de automóveis no país. Seis meses depois, a sua participação de mercado passou para $25 \%$ - um carro a cada quatro vendidos no Brasil - utilizavam esse sistema (MORAIS, 2004).

De acordo com Feldman (2003), o carro bi-combustível funciona a partir da utilização de equipamentos eletrônicos que analisam o tipo de combustível que existe no tanque do automóvel e a partir disto ajusta automaticamente o motor com o objetivo de atingir uma perfeita combustão. Assim, esse sistema permite que o consumidor possa escolher livremente com qual combustível abastecer o seu automóvel, de forma misturada entre os dois - em qualquer proporção - ou de forma separada para cada um deles de acordo com o seu desejo o que em muitas situações significa uma grande vantagem para o consumidor. (GRECO, 2003).

Em relação ao preço, para saber qual é o combustível mais barato proporcionalmente ao outro basta multiplicar o preço do litro da gasolina por 0,7 . Se o resultado final for maior do que o preço do litro do álcool, então proporcionalmente o álcool é mais barato que a gasolina e vice-versa em caso contrário (MORAIS, 2004).

Segundo Morais (2004), em 1985 cerca de 96\% dos automóveis fabricados no Brasil utilizam motores movidos a álcool. Contudo o desabastecimento de álcool combustível que ocorreu no início da década de 1990 e o aumento de preços sepultaram o desejo dos consumidores em comprar automóveis com esse tipo de motor.

Estudos apontam que $80 \%$ dos brasileiros optariam pelo motor bi-combustível se tivessem essa opção no momento da compra (AGÊNCIA AUTO PRESS, 2005). No ano de 2010 eles representaram cerca de $95 \%$ do mercado. Assim, apesar dos problemas que os carros movidos a álcool combustível proporcionaram aos seus donos e o fato de que o automóvel é um produto caro para os padrões brasileiros

- e por isso em princípio a sua compra é planejada e não por impulso -, o crescimento estrondoso do carro do carro bi-combustível no mercado brasileiro é surpreendente. É de extrema importância para o marketing conhecer o comportamento de compra dos consumidores e quais os fatores que compõem as teorias relativas à adoção de novos produtos são válidas para o consumidor de carros novos brasileiro. 


\section{JUSTIFICATIVA}

A compreensão do processo de compra do consumidor é de primordial importância para as empresas, pois, a partir deste processo é que o consumidor não só decide pela compra ou não do produto, como também decide quando e como comprar, além de decidir o quanto gastar. Assim, é possível coletar uma série de informações importantes que facilitarão o processo de escolha por parte dos consumidores para adoção do automóvel bi-combustível.

Outro ponto a ser considerado na justificativa para a realização deste projeto de pesquisa é a grande aceitação que este tipo de produto obteve junto ao mercado consumidor.

Em virtude da recentidade da existência dos motores bi-combustíveis, não existe um histórico de pesquisas sobre esse produto. Assim, esta pesquisa também se justifica pela sua atualidade e caráter inédito, pois se estudos existirem sobre este assunto, provavelmente estarão ainda em fase de elaboração ou conclusão. Além disso, as empresas automobilísticas já estão se preparando para o lançamento do automóvel tri-combustível que além da mistura entre álcool e gasolina, também aceitará o gás (CORREA, 2004). Isto significa que o estudo deste processo de adoção do motor bi-combustível por parte dos consumidores continua a ser de interesse do estudiosos de marketing e do setor automobilístico em função do fato de que o consumidor terá uma nova opção em breve no mercado e o que se puder conhecer acerca deste processo será útil num futuro bem próximo.

Por último, mas não menos importante, é preciso considerar o tamanho e a importância da indústria automobilística no Brasil, o qual é o $4^{\circ}$ maior mercado de automóveis e veículos leves do mundo (FENABRAVE, 2010) com um mercado de mais de 3,3 milhões de automóveis e veículos leves no ano de 2010. Em 2004, o Brasil era o $10^{\circ}$ maior mercado. Calcula-se que 200 mil empresas atuam no setor, desde montadoras a lojas de peças com a geração de 1,3 milhões de empregos em toda a cadeia produtiva. A arrecadação de impostos e contribuições é de cerca de 10 bilhões de reais por ano (CORREA, 2004).

\section{OBJETIVOS}

O objetivo - por meio desse estudo - é o de mensurar as características que favorecem a adoção do carro bi-combustível por parte dos consumidores descobrindo aquelas que são mais relevantes. A escolha dessas características leva em consideração a teoria da adoção de novos produtos e também os resultados da etapa qualitativa da pesquisa. Além disso, têm-se como objetivos específicos:

- Descrever os principais fatores ou dimensões que favorecem a adoção de novos produtos por parte dos clientes de acordo com a teoria existente sobre este assunto.

- Descrever as fases pelas quais os novos produtos devem passar para serem adotados pelos clientes de acordo com a teoria existente sobre este assunto.

- Identificar quais as principais vantagens do carro bi-combustível de acordo com a percepção dos consumidores.

- Conhecer o comportamento de compra dos clientes por meio de entrevistas com os mesmos e com profissionais do setor de compra e venda de veículos.

- Elaboração de uma escala para representar os fatores presentes na teoria para mensurar a percepção dos mesmos em relação a um determinado produto ou serviço.

- Verificar a confiabilidade interna da escala criada para cada uma dos fatores.

- Identificar quais são os fatores - dentro aqueles listados na teoria e também aqueles identificados na pesquisa qualitativa - que os consumidores consideram mais importantes. 
- Verificar por meio de análise fatorial se os fatores presentes na teoria do desenvolvimento de novos produtos estão presentes no processo de adoção de automóveis bi-combustíveis.

\section{REVISÃO TEÓRICA}

\subsection{ADOÇÃO E DIFUSÃO DE UM NOVO PRODUTO}

Os profissionais de marketing devem conhecer e entender o processo de adoção (decisões individuais que a pessoa toma antes de aceitar um produto) e difusão (processo de divulgação do novo produto na sociedade) de um novo produto pelo possível cliente (ETZEL; WALKER; STANTON, 2001), lembrando que o processo de adoção por parte do consumidor começa quando se encerra o processo de inovação por parte da empresa (KOTLER; KELLER, 2006). De acordo com a visão dos consumidores, um novo produto é aquele que é percebido como diferente quando comparado com os produtos atuais (BLACKWELL; MINIARD; ENGEL, 2005).

Conforme Sheth, Mittal e Newman (2001), o processo de adoção é dividido em quatro etapas: consciência, interesse, desejo e ação. Nesse caso, o consumidor passa por esses quatro estágios, os quais possuem uma hierarquia. Assim, em um primeiro momento os consumidores tomam consciência a respeito do novo produto. Em seguida ficam interessados pelos mesmos e posteriormente se sentem atraídos e compram esse novo produto.

Para Kotler e Keller (2006), os fabricantes devem facilitar a movimentação do consumidor através desses estágios. Diversas atividades podem ser feitas, entre elas experimentação do produto, amostras grátis e afins.

O ciclo de vida de um produto, segundo Giglio (2002), vem diminuindo em função do dinamismo e velocidade do mercado. Antigamente, os veículos eram projetados para ficarem cerca de dez anos no mercado, hoje novos modelos são lançados a cada dois anos, o que significa que possíveis clientes devem ser rapidamente identificados para o início, meio e fim do ciclo de vida do produto.

As inovações são classificadas em relação ao comportamento dos consumidores em três categorias (SOLOMON, 2010; BLACKWELL; MINIARD; ENGEL, 2005):

- Inovação Contínua: são pequenas modificações que ocorrem nos produtos atuais. Caracterizam-se por serem simples extensões de linha, oferecendo novas oportunidades de escolha e representam

- pequenas mudanças nos hábitos de consumo.

- Inovação Dinamicamente Continua: significa uma mudança mais pronunciada do que a inovação contínua e que influencia nos hábitos de vida e no manuseio dos produtos.

- Inovação Descontínua: são produtos que criam grandes mudanças na vida da população. São produtos realmente inovadores - e não simplesmente uma versão melhorada dos produtos atuais - no sentido de que substituem de forma plena os produtos anteriores.

De acordo com Martinez, Pólo e Flavian (1998) a primeira classificação de consumidores em relação às categorias de adoção de novos produtos foi elaborada por Bass em 1969, dividindo consumidores em dois grandes grupos: os inovadores (aqueles que determinam padrões de comportamento) e os imitadores (aqueles que seguem padrões de comportamento definidos pelo grupo anterior). Levando-se em consideração a complexidade dos mercados atuais, ampliou-se essa classificação, subdividindo-a em mais categorias (PETER; OLSON, 1999; SOLOMON, 2010; BLACKWELL; MINIARD; ENGEL, 2005; SETH; MITTAL; NEWMAN, 2001): 
- Inovadores: São pioneiros na utilização de um determinado produto inovador, mesmo correndo o risco de utilizarem um produto desconhecido, mas podendo desfrutar do status de serem os primeiros, modernos e aprenderem coisas novas. Estes clientes não são usados como referência, por terem um perfil jovem, arrojado, aventureiro e até mesmo, extravagante. São importantes porque influenciam os adotantes iniciais. Entretanto, devem ser consultados durante a fase de teste de novos produtos, antes do lançamento ao mercado potencial. Conforme Etzel, Walker e Stanton (2001), são indivíduos que confiam mais em propagandas do que em vendedores.

Compradores organizacionais inovadores pertencem às empresas que acreditam que sua produtividade está vinculada à utilização de novas idéias e tecnologias, ressaltam Churchill e Peter (2000). Realmente algumas organizações conseguem dobrar a produção com menor quantidade de equipamentos, porém mais modernos.

- $\quad$ Adotantes iniciais: São pessoas formadoras de opinião. Aceleram a difusão dos produtos, uma vez que têm credibilidade, posição social de destaque, grande conhecimento e poder aquisitivo. “... tendem a ser formadores de opinião e modelos para os outros, como boas habilidades sociais e respeitados dentro de grandes sistemas sociais" (BLACKWELL; MINIARD; ENGEL, 2005, p.442). Estas pessoas devem ser identificadas pelas empresas para a realização de ações de incentivo, apoio e esclarecimento.

- Maioria inicial: São os consumidores típicos do produto e responsáveis por grandes volumes de compra. Possuem maior poder aquisitivo e se baseiam nas propagandas e experiências dos adotantes iniciais durante o processo de tomada de decisão. As empresas devem satisfazer plenamente este grupo e torná-lo fiel.

- Maioria tardia: Geralmente os consumidores que compõem este grupo, possuem menor poder aquisitivo e perfil cético e conservador. São insensíveis às inovações tecnológicas e passam a comprar o produto por pressão da sociedade ou devido à queda dos preços.

- Retardatários: Este grupo é caracterizado por pessoas com pequeno poder aquisitivo, idosas e moradores das áreas rurais. São tradicionais e compram apenas um produto já estabelecido no mercado, conforme Churchill e Peter (2000). Não necessitam de uma estratégia de marketing específica uma vez que são os últimos a adquirirem o produto e sua contribuição nas vendas é muito pequena.

Para Giglio (2002), o conhecimento dos consumidores que são os primeiros a adotar novos produtos pioneiramente facilita a criação de estratégias de marketing, direcionadas e bem sucedidas, apesar de cada categoria de consumidores ter suas peculiaridades. Assim, uma crítica ao modelo de difusão de inovações ressalta a diferença de comportamentos para produtos distintos, ou seja, um comprador retardatário de um determinado produto pode ser um inovador em outro.

Em relação ao caráter revolucionário dos produtos, segundo Aggarwal, Cha e Wilemon (1998) quanto maior o nível de ruptura dos novos produtos, pior tende a ser sua avaliação pelos consumidores. Isto explica porque alguns produtos em um primeiro momento são mal avaliados e, com o passar do tempo, são melhor avaliados pelo público e consumidos em maior ou larga escala. Além disso, uma grande ruptura torna o processo de busca de informações por parte dos consumidores mais lento, incerto e trabalhoso.

\subsection{CARACTERÍSTICAS QUE AFETAM A TAXA DE ADOÇÃO}

Existem cinco características que podem afetar o processo de adoção ao novo produto, principalmente se ele for uma inovação no mercado (PETER; OLSON, 1999; SOLOMON; 2010; 
BLACKWELL; MINIARD; ENGEL, 2005; SETH; MITTAL; NEWMAN, 2001; ETZEL; WALKER; STANTON, 2001). São elas:

Vantagem relativa: Grau de vantagem que uma inovação oferece em relação aos produtos disponíveis no mercado. A sua percepção por parte dos consumidores ao comparar os novos produtos com os já existentes tem grande influência na taxa de adoção. Esta vantagem pode estar presente no custo mais baixo, segurança oferecida, facilidade de utilização, etc. De acordo com Blackwell, Miniard e Engel (2005), esta é a característica mais importante que os novos produtos devem possuir em relação aos convencionais.

- Compatibilidade: grau em que o produto é compatível com os valores e experiências dos indivíduos da comunidade (KOTLER; KELLER, 2006). A incompatibilidade pode surgir quando os produtos utilizados atualmente não atendem as necessidades e expectativas dos consumidores (AGGARWAL; CHA; WILEMON, 1998).

- Complexidade: Pode ser entendida como o grau de dificuldade que os consumidores sentirão para utilizar o novo produto, isto significa que quanto mais complexo o produto for percebido pelos clientes, mais demorada será a sua adoção. Em países onde o nível de educação e/ou alfabetização é baixo, a alta complexidade percebida pelo público-alvo pode diminuir a taxa de adoção de alguns produtos. Equipamentos eletrônicos têm problemas em relação a esta característica, uma vez que a dificuldade em entender e/ou utilizar um novo produto pode atrapalhar sua adoção pelos consumidores. A dificuldade e o nível técnico das instruções contidas nos manuais dos novos produtos também são importantes para a formação dessa característica.

Possibilidade de experimentar (divisibilidade): Caracteriza-se pela capacidade de um novo produto ser experimentado com pouco esforço (tempo, recursos financeiros, conhecimento e afins). Geralmente os produtos mais caros têm taxa de adoção menor ou mais lenta por causa desta característica, ou seja, quanto maior a possibilidade do cliente experimentar e testar um novo produto, desconsiderando as outras características, melhor será seu percentual de adoção. As amostras grátis são um ótimo instrumento para auxiliar na experimentação por parte dos clientes.

- Comunicabilidade: Expor um produto em funcionamento aumenta a taxa adoção. Se os resultados do uso do novo produto são facilmente identificados pelos indivíduos, e comunicados pelos mesmos, então a possibilidade de sucesso de novo produto é bem maior. É importante identificar o nível de percepção dos benefícios de um novo produto por parte do seu mercado potencial.

Além das características citadas acima, Peter e Olson (1999) descrevem outras duas características que afetam a taxa de adoção de novos produtos:

- Velocidade: refere-se à rapidez que os benefícios do novo produto poderão ser observados ou percebidos pelos consumidores. Isso é importante, pois, muitos consumidores não querem esperar muito tempo para poderem sentir e experimentar os benefícios de um produto. Um exemplo clássico são os programas de emagrecimento, que prometem resultados em uma semana.

Simbolismo: diz respeito ao que significa para o consumidor a utilização de um novo produto ou uma nova marca. Esse significado é formado ao comprar ou utilizar esse novo produto. Nesse caso, os significados sociais e psicológicos são mais importantes do que as características técnicas do produto.

Para Mowen e Minor (2003, p.286):

Os mesmos fatores que influenciam o provável sucesso de uma inovação também influenciam a rapidez com a qual ela é adotada. O produto será adotado mais 
rapidamente à medida que satisfizer uma necessidade, for compatível, tiver uma vantagem relativa, for menos complexo, tiver aspectos positivos notáveis e puder ser facilmente experimentado.

De acordo com Seth, Mittal e Newman (2001), as principais resistências às inovações são o hábito e o risco. Em relação ao primeiro, pode-se considerar que o consumidor age de uma determinada maneira, aprendida anteriormente, sempre que se encontra na mesma situação anterior ou é estimulado da mesma forma novamente.

Em relação aos riscos são percebidos como algo que pode dar errado ou como conseqüências indesejáveis de uma ação de compra e utilização dos produtos. Os mesmos foram classificados como riscos de desempenho, onde os produtos não apresentam o desempenho anteriormente previsto por parte dos consumidores. Além disso, tem-se também os riscos sociais, ou seja, a preocupação com a opinião e aprovação dos indivíduos que formam a sociedade, classes social, família, grupos de convívio e afins, nos quais o consumidor pertence ou se relaciona (SETH; MITTAL; NEWMAN, 2001).

Outro aspecto destacado por Aggarwal, Cha e Wilemon (1998) é que as novas tecnologias são vistas pelos consumidores como um fator de risco. Obviamente, quanto maior o risco percebido, maior será a dificuldade de adoção de novos produtos. Além disso, estes autores observam que a adoção de novos produtos requer uma aprendizagem dos consumidores acerca dos mesmos (às vezes requer até mesmo um grande esforço cognitivo). Assim, a possibilidade do cliente experimentar um produto pode ser fundamental para que o consumidor possa conhecê-lo melhor. Outro ponto a ser considerado é que a comunicabilidade também é fundamental para que o público-alvo não só possa receber a informação pertinente, mas também tenha condições de compreendê-la e memorizá-la.

Por último, mas não menos importante Chao e Gupta (1995) e Ahmed et al. (2004) descrevem a importância do país de origem do produto. Esse fator, de acordo com estes pesquisadores influencia fortemente a taxa de adoção de produtos estrangeiros em novos mercados e as crenças, percepções e atitudes dos consumidores em relação ao país de origem dos mesmos.

\section{METODOLOGIA}

\subsection{METODOLOGIA DE PESQUISA}

Essa é uma pesquisa descritiva e, segundo Malhotra (2001), é um tipo de pesquisa conclusiva cujo maior objetivo é a descrição de algo, usualmente características de mercado ou funções.

A pesquisa teve duas etapas. A primeira etapa, qualitativa, consiste na consulta de bibliografia sobre o assunto, análise de pesquisas qualitativas com os consumidores de automóveis e profissionais do setor de venda de automóveis. A segunda etapa corresponde à pesquisa quantitativa, descritiva (survey) feita junto aos consumidores de automóveis.

Com o objetivo de melhor conhecer as opiniões, os critérios de escolha, a percepção de risco ao comprar automóveis bi-combustíveis e afins, foram realizadas 10 entrevistas com consumidores, gerentes e vendedores de automóveis, com o objetivo de conhecer melhor o problema e a opinião dos mesmos em relação ao comportamento de compra dos indivíduos para esse tipo de produto. Todas as entrevistas foram gravadas em fita cassete. A partir dos dados obtidos nesta pesquisa, foi possível elaborar o instrumento de coleta de dados - questionário - adequado para que se atinja os objetivos desta pesquisa, além de proporcionar uma melhor visão e compreensão a respeito do contexto do problema.

Em relação às entrevistas, Marconi e Lakatos (1986) descrevem que elas ocorrem com o encontro de duas pessoas, portanto é uma conversação realizada face-a-face, em que uma destas obtém as 
informações que deseja da outra pessoa, através de uma conversa de natureza profissional e de forma metódica. Para Andrade (1997), a entrevista tem algumas vantagens sobre outras técnicas, devido ao fato de que pode ser utilizada com pessoas de todos os segmentos sociais. O entrevistador pode esclarecer e tirar dúvidas do entrevistado acerca das perguntas propostas, pode-se observar gestos, atitudes e reações do entrevistado.

A entrevista focalizada pode entendida também para qualquer entrevista, na qual o entrevistador, de antemão, tenha ciência dos aspectos de uma experiência que será discutida com o entrevistado (SELLTIZ et al., 2005). Ainda, de acordo com esses autores, a entrevista focalizada é realizada através de uma lista de tópicos que devem ser abrangidos, mas o entrevistador determina a ordem e a maneira de propor as perguntas.

Neste trabalho será também utilizado o contato pessoal tendo como instrumento de coleta de dados o questionário. Segundo texto de Marconi e Lakatos (1986) a elaboração de um questionário requer a observância de normas precisas, a fim de aumentar sua eficácia e validade. Em sua organização deve-se levar em conta os tipos, a ordem, os grupos de perguntas, a formulação das mesmas e também tudo que se sabe sobre percepção, estereótipos, mecanismos de defesa, liderança e etc.

Após a elaboração do instrumento de coleta dos dados, foi realizado o pré-teste -do questionário junto aos consumidores de automóveis. Os resultados além de servirem de embasamento para alterações e melhorias no questionário original, também foram utilizados para o cálculo do tamanho representativo da amostra. Assim, foram aplicados 35 questionários, com o intuito de se identificar os problemas e pontos duvidosos que os mesmos apresentavam para os respondentes.

Foram seguidas as técnicas recomendadas por Malhotra (2006) que descreve que o propósito do pré-teste é o de melhorar o questionário pela identificação e eliminação de problemas em potencial. O préteste deve ser realizado junto ao mesmo público-alvo da pesquisa, ou seja, a amostra do pré-teste deve possuir as mesmas características da amostra a ser pesquisada.

As unidades de observação são os compradores de automóveis e profissionais que atuam no setor. As unidades de análise são os consumidores brasileiros de carros bi-combustíveis. A aplicação dos questionários, bem como as entrevistas, ocorreu em uma metrópole da região sudeste do Brasil. Contudo, apesar da unidade de análise se referir aos consumidores brasileiros, a amostragem utilizada não foi probabilística, pois, a mesma não garante a completa aleatoriedade dos dados obtidos. A realização da pesquisa ocorreu em alguns pontos dessa metrópole, sendo que a sua escolha deveu-se a conveniência e aquiescência de lojas e concessionárias de veículos em realizar a pesquisa. Assim, essa amostra é classificada como por conveniência, a qual segundo Malhotra (2006), é uma amostragem não probabilística, em que a seleção das unidades amostrais é baseada na obtenção de elementos convenientes, ou seja, eles estão no lugar adequado no momento oportuno. É a mais rápida e mais barata, pois os elementos são fáceis de encontrar e rápidos de encontrar.

Para o cálculo do tamanho da amostra considerou-se a fórmula de determinação do tamanho pela média, extraída de Malhotra (2006) :

$$
\mathrm{n}=\mathrm{P}^{2} \cdot \mathrm{z}^{2}
$$

$\mathrm{D}^{2}$

Onde n é o tamanho da amostra.

D representa o nível de precisão.

$\mathrm{Z}$ representa o intervalo de confiança.

P representa o desvio padrão. 
No presente estudo, o nível de precisão foi de 0,5 pontos, sendo que o intervalo de confiança é de $95 \%$ e o valor de $Z=1,96$ (teste $Z$ ). O maior desvio padrão encontrado foi de 4,12 - utilizando-se uma escala de zero a dez pontos. Por conseguinte, o tamanho final da amostra foi de 260,7 questionários, sendo que se obteve 261 questionários válidos.

A variância considerada foi o valor resultante da análise das perguntas que formam o questionário submetido ao pré-teste. Em seguida calcula-se o desvio padrão referente a essas perguntas - escolhendo-se a maior variância encontrada entre as mesmas, ou seja, escolhendo-se a pergunta que apresenta a menor homogeneidade (maior heterogeneidade) de acordo com o público-alvo da pesquisa.

\subsection{VALIDADE DO CONTEÚDO}

Uma escala, a qual tenha a finalidade de medir a intensidade ou presença de um determinado construto deve passar por uma avaliação do seu conteúdo, ou seja, avalia-se a correspondência entre os itens - de forma individual - que estão presentes na escala e a sua definição conceitual. Apesar de ser uma atividade bastante subjetiva, na qual o pesquisador verifica se os itens que compõem a escala realmente abrangem todo o seu possível conteúdo, sem faltar algum aspecto importante desse construto. É importante notar que enquanto a confiabilidade se atém a como medir algo - consistência das medidas -, a validade diz respeito ao que deve ser medido - o quanto o conceito é bem definido pelas medidas (HAIR et al., 2009; MALHOTRA, 2006).

Em outras palavras, a validade verifica se as diferenças observadas em relação às mensurações de um determinado objeto realmente refletem as diferenças de opinião ou percepção de diferentes entrevistados, enquanto que a confiabilidade garante que os meios utilizados para a medição do objeto ou construto realmente indicam as diferenças de percepção dos respondentes. A confiabilidade é uma condição necessária, mas ela não garante a existência da validade. Por outro lado, se uma medida é valida, ela então será confiável. (CHURCHILL JR., 1979).

De acordo com Churchill Jr. (1979), para que o pesquisador possa criar instrumentos adequados à mensuração de fenômenos, é necessário um grande conhecimento a respeito do domínio ou escopo do problema. Além disso, como passo seguinte, esse autor descreve que a formação dos itens que irão compor a escala, a qual deverá capturar as medidas ou valores do construto. Em ambas as atividades, em geral, utiliza-se de pesquisa exploratória por meio da revisão da literatura e meios qualitativos com o público-alvo relacionado com o construto (por exemplo, consumidores, pais, mães, alunos, etc.), professores, especialistas e profissionais do ramo de negócios, se for o caso.

Além disso, nesse estudo, foram analisadas as descrições dos fatores que afetam o processo de adoção de novos produtos por parte dos consumidores. Além disso, as enunciados das questões que formam os construtos foram revisados por outros dois professores de marketing.

\subsection{OPERACIONALIZAÇÃO DOS CONSTRUTOS}

A teoria da adoção de novos produtos preconiza que existem cinco fatores principais que são os responsáveis pela melhoria na adoção de novos produtos. Além disso, por meio da pesquisa qualitativa identificou-se que o status também é um fator importante, no caso dessa pesquisa, para adquirir automóveis novos bi-combustíveis. Assim, esses seis fatores formaram os construtos - vantagem relativa, compatibilidade, complexidade, divisibilidade, comunicabilidade e status, os quais foram representados pelas seguintes afirmativas:

Status: O carro bi-combustível tem mais status do que um carro movido só a gasolina; as outras pessoas reparam/percebem se eu tenho um carro bi-combustível; eu me sinto mais importante por ter um 
carro bi-combustível do que antes quando eu não tinha; e ter um carro bi-combustível é um sinal de prestígio. Essas afirmativas correspondem às questões 1, 8, 13, e 20 respectivamente.

- Vantagem relativa: O carro bi-combustível apresenta vantagens em relação ao carro movido somente à gasolina; o carro bi-combustível tem vantagens importantes em relação ao carro movido somente à gasolina; o carro bi-combustível é melhor do que o carro comum; o carro bi-combustível é superior ao carro movido somente a gasolina; e a relação custo/benefício do carro bi-combustível é positiva. Essas afirmativas correspondem às questões 5, 9, 16, 18 e 24 respectivamente.

- $\quad$ Compatibilidade: O carro bi-combustível é compatível com o seu jeito de viver a vida; o carro bicombustível é coerente com o meu estilo de vida; e a minha personalidade me fez interessar em possuir um carro bi-combustível. Essas afirmativas correspondem às questões 4, 10 e 22 respectivamente.

- Complexidade: É fácil de entender como o carro bi-combustível funciona; o carro bi-combustível não apresenta dificuldades para dirigi-lo; o carro bi-combustível é fácil de ser utilizado; e dirigir um carro bi-combustível é igual a dirigir um carro comum. Essas afirmativas correspondem às questões 14, 15, $17 \mathrm{e}$ 23 respectivamente.

- Divisibilidade: Quando se vai comprar um carro bi-combustível é fácil experimentá-lo; é fácil testar o carro bi-combustível antes de comprá-lo; é fácil de verificar o carro bi-combustível através de um test-drive; e na hora da compra, é fácil provar o carro de bi-combustível dirigindo o mesmo. Essas afirmativas correspondem às questões $3,6,12$ e 25 respectivamente.

- Comunicabilidade: Eu conheço as diferenças entre o carro bi-combustível e os outros carros; existem muitas reportagens em revistas e jornais que ajudam a explicar as diferenças e as vantagens/desvantagens do carro bi-combustível; as diferenças que existem entre os carros bi combustíveis e os carros comuns são amplamente divulgadas pela imprensa; é fácil para os vendedores descrever as diferenças e vantagens/desvantagens do carro bi-combustível; e no momento da compra, não tive muitas dúvidas a respeito do carro bi-combustível. Essas afirmativas correspondem às questões 2, 7 , 11,19 e 21 respectivamente.

Os construtos acima, bem como suas respectivas questões foram representadas por uma escala do tipo likert, com valores variando de 0 a 10, tendo como âncoras as expressões "discordo totalmente" e "concordo totalmente", respectivamente.

\section{ANÁLISE DOS DADOS}

\subsection{PESQUISA QUALITATIVA}

Por meio das entrevistas, observou-se que a maioria dos profissionais de comercialização de veículos não possui conseguiu ainda traçar um perfil específico do consumidor de carro bi-combustível. Por outro lado, percebeu-se entre os grupos de entrevistados - cliente e profissionais da área - que os fatores sociais, notadamente o status exercem uma forte influência sobre os que procuram esse tipo de produto.

Em termos dos papéis dos consumidores e influências sociais e familiares, identificou-se que os maridos, irmãos, pais e amigos - portanto, pessoas do sexo masculino - são capazes de interferir fortemente no processo de compra, principalmente quando esses últimos são mulheres.

Com relação às dúvidas mais freqüentes, observou-se que o consumidor desse tipo de produto apresentou apenas indagações em relação ao funcionamento e manuseio, como por exemplo, se existia dois tanques ou se haveria necessidade de esperar um combustível acabar para colocar o outro. As grandes vantagens do carro bi-combustível destacada pelos entrevistados é a possibilidade de economia em função da variação do preço da gasolina e do álcool, bem como pela maior possibilidade de escolha.

Nucleus, v.9, n.1, abr.2012 
Outro fato interessante diz respeito ao processo de busca de informações por parte dos consumidores. Grande parte desses últimos utilizou cadernos especializados de jornais, revistas especializadas e opiniões de amigos e familiares para aprender e compreender melhor essa novidade. Em muitas ocasiões, o tempo médio para se concretizar a venda de um automóvel, depende mais da quantidade e qualidade das informações disponíveis para o consumidor, do que o modelo ou marca do veículo.

Um comportamento interessante narrado pelos profissionais de vendas de veículos, está relacionado com o status. Quando o carro bi-combustível foi lançado no mercado, a procura pelo mesmo foi grande. Mas a grande vantagem que os consumidores percebiam não estava associada ao novo tipo de motor, e sim, à novidade de mercado. Com o passar do tempo, esse tipo de comportamento deixou de ser observado e as vantagens do motor bi-combustível se tornaram o principal fator pela escolha desse tipo de produto por parte dos consumidores - principalmente a relação consumo-desempenho-preço do combustível.

\subsection{TRATAMENTO DOS DADOS E CARACTERÍSTICAS DA AMOSTRA}

O objetivo é identificar se as questões não-respondidas ou respondidas parcialmente pelos entrevistados podem comprometer as análises a serem realizadas, bem como descobrir possíveis tendências no não preenchimento destas questões. Esse fato pode causar viéses nas inferências encontradas na amostra estudada, bem como pode acarretar uma diminuição na confiabilidade das análises estatísticas conduzidas em decorrência da redução do tamanho da amostra. A aleatoriedade da ausência de dados de uma amostra é um pressuposto importante. Isto significa que não existe uma diferença sistemática entre os dados coletados e os dados ausentes, ou seja, ambos são um subconjunto aleatório dos elementos que compõem todo o universo de pesquisa (NEWTON; RUDESTAM, 1999).

Assim, foi realizada uma análise descritiva dos dados faltantes para cada variável. Nenhuma questão apresentou um índice superior a 5\% de dados faltantes - em números absolutos, 13 respostas de um total de 261 questionários.

Caso alguma variável tivesse apresentado mais do que 5\% de dados ausentes, seria realizado um teste $\mathrm{t}$ entre os questionários nos quais a variável está ausente e presente para verificar se existe alguma diferença estatisticamente significativa. Contudo, de acordo com Tabachnick e Fidel (2001), somente as variáveis com mais de 5\% de dados faltantes devem ser consideradas na análise do teste $\mathrm{t}$ de aleatoriedade.

Além disso, foi realizado o Teste Little's MCAR. Para Hair et al. (2009) este teste permite verificar se o comportamento dos dados ausentes é completamente ao acaso (AACA - nível mais alto de aleatoriedade de dados), ou seja, se realmente os valores observados para uma variável qualquer representam uma amostra aleatória para todos os valores existentes desta variável. Assim, este teste analisa os padrões de ausência de dados de todas as variáveis e os compara com os valores esperados em relação ao processo aleatório de dados ausentes. Como o resultado obtido foi de um sig. de 0.000 não é possível considerar os dados ausentes completamente ao acaso e utilizar métodos de correção e imputação de dados.

Outro pressuposto que deve ser verificado é o padrão de distribuição das variáveis estudadas. Para tal, foi realizado o teste de normalidade de Kolmogorov-Smirnov para as variáveis que compõem a escala de adoção automóveis bi-combustíveis (25 itens no total), bem como para as opções que classificam as dimensões mais importantes para a escolha desse produto (6 opções). Todas elas apresentaram um sig. de 0.000, o que indica que nenhuma dessas variáveis - 31 no total - possui uma distribuição normal. 
Em relação às características da amostra, a grande maioria dos entrevistados são homens (82\%"), casados ou vivem em uma união estável (52,1\%), apresentam a idade entre 26 e 49 anos (72,5\%), já terminaram o ensino médio ou superior $(72,8 \%)$ e cerca de $50 \%$ possui rendimentos acima de $\mathrm{R} \$$ $3.150,00$.

\subsection{PESQUISA QUANTITATIVA}

O primeiro passo compreende analisar a confiabilidade da escala para mensurar os seis construtos que representam a percepção do consumidor acerca dos automóveis bi-combustíveis. Por confiabilidade da escala, entende-se a capacidade da mesma gerar resultados consistentes ao longo do tempo (MALHOTRA, 2006). Isto significa que a escala deve apresentar resultados semelhantes para pessoas que possuem a mesma opinião à respeito dos diversos itens - questões - contidas na mesma, que em geral estão relacionadas a um construto.

O valor do Alpha de Cronbach varia entre 0 e 1. Para Pestana e Gageiro (2000) o seu valor como indicador de boa consistência interna deve estar acima de 0.80. Para Hair et al. (2009) valores entre $1.00 \mathrm{e}$ 0.70 são aceitáveis, sendo que em pesquisas exploratórias pode se aceitar valores de até 0.60 . Malhotra (2006) considera que o valor do Alpha deve estar entre 0.60 e 1.00. Por outro lado, Morgan e Griego (1998) afirmam que o valor do Alpha estiver acima de 0.90 é provável que a escala utilizada apresente muitos itens repetidos ou então que o pesquisador está utilizando um número maior de itens do que o realmente necessário. Os resultados obtidos estão sumarizados no quadro abaixo:

Tabela 1 - Valores do Alpha de Cronbach para a escala que representa os construtos relacionados com a adoção de novos produtos.

\begin{tabular}{|c|c|c|}
\hline Construto & Valor & Observação \\
\hline Status & .8684 & $\begin{array}{l}\text { A retirada de itens da escala não aumento o valor do Alpha de } \\
\text { Cronbach }\end{array}$ \\
\hline $\begin{array}{l}\text { Vantagem } \\
\text { Relativa }\end{array}$ & .9257 & $\begin{array}{l}\text { A retirada de itens da escala não aumento o valor do Alpha de } \\
\text { Cronbach }\end{array}$ \\
\hline Compatibilidade & .8238 & A retirada da questão 22 aumenta o valor para .8723 \\
\hline Complexidade & .8682 & A retirada da questão 14 aumenta o valor para .8889 \\
\hline Divisibilidade & .8894 & $\begin{array}{l}\text { A retirada de itens da escala não aumento o valor do Alpha de } \\
\text { Cronbach }\end{array}$ \\
\hline $\begin{array}{l}\text { Comunicabilidad } \\
\mathrm{e}\end{array}$ & .7389 & A retirada da questão 2 aumenta o valor para .8770 \\
\hline
\end{tabular}

Analisando-se o quadro acima, é possível concluir que todas as dimensões utilizadas para compor a escala, possuem valores de Alpha de Cronbach considerados satisfatórios e assim verifica-se que esta escala possui uma boa consistência interna.

A percepção dos consumidores em relação à associação de cada uma das dimensões estudadas, presentes nos carros bi-combustíveis é apresentada a seguir. É importante considerar ainda o intervalo de precisão de 0,5 pontos para cima ou para baixo para os valores obtidos - com $95 \%$ de confiabilidade. 
Tabela 2 - Percepção dos fatores pelos consumidores em relação aos carros bi-combustíveis

\begin{tabular}{l|c}
\hline \multicolumn{1}{c|}{ Atributos } & Média \\
\hline Divisibilidade & 7,10 \\
Complexidade & 6,65 \\
Status & 6,57 \\
Compatibilidade & 6,23 \\
Comunicabilidade & 6,15 \\
Vantagem Relativa & 5,67 \\
\hline
\end{tabular}

Fonte: Dados da Pesquisa.

Um outro objetivo da pesquisa, é o de verificar quais dessas dimensões são mais importantes para os consumidores. É importante considerar ainda o intervalo de precisão de 0,5 pontos para cima ou para baixo para os valores obtidos - com 95\% de confiabilidade. Os resultados obtidos são exibidos abaixo:

Tabela 3 - Dimensões considerados mais importantes pelos consumidores

\begin{tabular}{l|c}
\hline \multicolumn{1}{c|}{ Atributos } & Média \\
\hline Complexidade & 7,12 \\
Divisibilidade & 6,77 \\
Comunicabilidade & 6,75 \\
Vantagem Relativa & 6,54 \\
Compatibilidade & 6,34 \\
Status & 5,59 \\
\hline
\end{tabular}

Fonte: Dados da Pesquisa.

Assim, observa-se que a facilidade em utilizar o automóvel bi-combustível, bem como a possibilidade de experimentá-lo e conhecer de forma clara as vantagens do mesmo, são as dimensões que os consumidores consideram mais presentes nesse produto.

Outra questão dessa pesquisa, também se atém aos atributos considerados mais importantes de um carro bi-combustível por parte dos consumidores. No entanto, as alternativas utilizadas nessa questão foram obtidas a partir da pesquisa qualitativa.

Tabela 4 - Atributos considerados mais importantes pelos consumidores

\begin{tabular}{l|cc}
\hline \multicolumn{1}{c|}{ Atributos } & Frequência & Média \\
\hline Economia & 37 & 14,2 \\
Praticidade & 27 & 10,3 \\
Modernidade & 42 & 16,1 \\
Novidade & 54 & 20,7 \\
Tecnologia & 58 & 22,2 \\
Inovação & 37 & 14,2 \\
Outros & 3 & 1,1 \\
\hline
\end{tabular}

Fonte: Dados da Pesquisa.

De acordo com o quadro acima, observa-se que a economia e praticidade são os fatores considerados mais importantes pelos respondentes. Também é possível destacar a modernidade, a tecnologia e a novidade que estão presentes nesse produto. 
Por fim, é realizada uma análise fatorial para identificar se as dimensões existentes na teoria realmente são percebidas pelos consumidores. Segundo Hair et al. (2009), o tamanho da amostra deve ser de no mínimo 5 observações para cada variável, sendo que o ideal seria de 10 a 20 observações por variável. Como são 25 variáveis e foram aplicados 261 questionários, esse pressuposto é atendido.

Além disso, como as variáveis são reduzidas a partir da técnica de análise fatorial, as mesmas devem possuir algum nível de multicolinearidade entre si. Assim, ao realizar os cálculos da análise fatorial o pesquisador deve elaborar a matriz de correlação entre essas variáveis, e a mesma deve apresentar um número substancial de variáveis com correlação igual ou acima de 0.30 . Outro pressuposto que deve ser verificado é o Teste de Esfericidade de Barlett o qual deve ser significante em nível de 95\%, ou seja, menor do 0,05 (MORGAN; GRIEGO, 1998). Este teste verifica se a hipótese de que as variáveis utilizadas na análise fatorial não são correlacionadas (MALHOTRA, 2006). Além disto, Hair et al. (2009) colocam que a Medida de Adequacidade da Amostra de Kaiser-Meyer-Olkin (KMO) deve ser também calculada e possuir valor acima de 0,80 , sendo para valores acima de 0,90 são considerados muito bons por Pestana e Gageiro (2000).

$\mathrm{O}$ valor obtido nessa pesquisa para a medida KMO foi de 0,919 e para o Teste de Efericidade de Bartlett apresentou uma sig. de 0,000 . Em relação à correlação entre as variáveis, mais de $80 \%$ das mesmas estão acima de 0,30 .

Foi utilizado o método de extração Fatoração dos eixos Principais. Este tipo de fatoração deve ser utilizado quando o objetivo é o de identificar os fatores (ou dimensões) essenciais geralmente embasados por uma teoria em relação às variáveis originais. Para facilitar a visualização e interpretação dos fatores, foram realizadas rotações ortogonais pelo método Varimax.

A análise fatorial não indicou o número de fatores a serem gerados. Assim, o critério escolhido foi o da raiz latente, no qual os autovalores com valor igual ou superior a 1 são retidos como fatores. Assim, foram gerados 4 fatores com autovalor acima de 1 e a variância explicada por esses fatores é de 71,98\% do total observado.A partir deste resultado, já é possível observar que nesta pesquisa não foram encontradas as 6 dimensões propostas na escala aplicada.

Considerando somente os valores com carga acima de 0,40 (HAIR et al., 2009) e quando esse valor é ultrapassado considera-se o fator com o maior valor. Os resultados foram os seguintes - as questões estão descritas no tópico metodologia:

- Fator 1: questões 2,3,14,15,17,19, 21 e 23.

- Fator 2: questões 1,6,12,13, 20, 22 e 25 .

- Fator 3: questões 4,5,9,10, 16,18 e 24 .

- Fator 4: questões 7,8 e 11.

Assim, o fator 1 apresenta fatores das dimensões comunicabilidade (3 ocorrências), divisibilidade (1 ocorrência) e complexidade (4 ocorrências).

O fator 2 apresenta fatores das dimensões status ( 3 ocorrências), divisibilidade ( 3 ocorrências) e compatibilidade ( 1 ocorrência).

O fator 3 apresenta fatores das dimensões compatibilidade ( 2 ocorrências), vantagem relativa (5 ocorrências).

O fator 4 apresenta fatores das dimensões status (1 ocorrência) e comunicabilidade ( 2 ocorrências).

O mais interessante, nesses resultados é que o fator 1 apresenta todas as ocorrências da escala complexidade e o fator 3 engloba todas as ocorrências da vantagem relativa. $\mathrm{O}$ fator 2 tanto os fatores status e divisibilidade, enquanto que o fator 4 apresenta uma predominância da dimensão comunicabilidade. 


\section{CONCLUSÃO}

Em termos práticos, verifica-se que os atributos que os consumidores mais valorizam são economia, praticidade e modernidade. De acordo com os dados da pesquisa, é necessário então, que os profissionais de marketing façam com que os consumidores percebam de forma mais clara esses benefícios e ao mesmo tempo associem de forma mais contundente os automóveis bi-combustíveis com os fatores ou dimensões que representam os atributos mais valorizados pelos mesmos. Isso pode ser feito em todos os chamados 4p's de marketing. Por meio de uma comunicação mais eficiente, melhores argumentos de venda, definição de preço que reflita as vantagens e posicionamento do produto, bem como pelo desenvolvimento de marcas associadas aos fatores considerados mais importantes por parte dos clientes.

Em termos teóricos, esse trabalho apresenta resultados muito interessantes. Em primeiro lugar, a escala elaborada considerou aspectos teóricos e resultados qualitativos obtidos por meio de entrevista com consumidores de automóveis e profissionais desse mercado. A escala apresentou bons resultados de confiabilidade interna.

Resultados promissores também foram obtidos com a realização da análise fatorial. Foram identificados quatro fatores que englobam as seis dimensões propostas pela escala. É importante ressaltar que dois fatores obtidos - fator 1 e 3 - englobam as dimensões complexidade e vantagem relativa. Interessante também é ressaltar que se a dimensão obtida por meio da pesquisa qualitativa (status) não for considerada na avaliação dos resultados, o fator 2 quase engloba toda a dimensão divisibilidade. E se a questão 22 for retirada, além de melhorar o índice de confiabilidade da escala, irá tornar o fator 2 específico da dimensão confiabilidade. Por isso, novas versões da escala são promissores, para se conseguir obter os resultados teóricos desejados.

Essa é a primeira versão da escala, Pode-se conseguiu diversos melhoramentos por meio da melhor descrição das afirmativas para os diversos construtos, inclusão, substituição e eliminação das questões que não apresentaram boa confiabilidade interna. Assim, novos estudos poderão e deverão contribuir de forma significativa para o desenvolvimento da escala com o intuito de mensurar e, portanto, conhecer a percepção dos consumidores acerca do nível de associação dos novos produtos, com os fatores que incentivam a sua aceitação por parte do mercado.

\section{REFERÊNCIAS}

AAKER, D.; KUMBAR, V.; DAY, G. S. Pesquisa de marketing. São Paulo: Atlas, 2001.

AGÊNCIA AUTO PRESS. De dose em dose. Pampulha, Belo Horizonte, 16/ 22 abr. 2005. Veículos, p.9.

AGGARWAL, P.; CHA, T.; WILEMON, D. Barries To The Adoption of Really-New Products and The Role of Surrogate Buyers. The Journal of Consumer Marketing. v. 15, n. 4, p. 358-372, 1998.

AHMED, Z.U. et al. Does country of origin matter for low-involvement products? International Marketing Review, v. 21, n. 1, p. $102-120,2004$.

BLACKWELL, R. D.; MINIARD, P. W.; ENGEL, J. F. Comportamento do consumidor. São Paulo: Pioneira Thomson Learning, 2005.

CHAO, P.; GUPTA, P. B. Information search and efficiency of consumer choices of new cars: country-oforigin effects. International Marketing Review, v.12, n.6, p. 47-59, 1995.

CHURCHILL JR., G. A. A Paradigm for developing better measures of marketing constructs. Journal of Marketing Research, v. 16, n.2, p. 64-73, fev. 1979. 
CHURCHILL JR., G. A.; PETER, J. P., Marketing: criando valor para os clientes. São Paulo: Saraiva, 2000 .

CORREA, C. As dificuldades de quem produz carros. Exame. São Paulo, n. 827, set. 2004.

ETZEL, M. J.; WALKER, B. J.; STANTON, W. J. Marketing. São Paulo: Makron Books, 2001.

FELDMAN, B. Flex-Fuel: você ainda vai ter um. Estado de Minas, Belo Horizonte, 20/03/2003. Veículos, p.2.

FENABRAVE (Federação Nacional da Distribuição de Veículos Automotores). Anuário 2010. São Paulo: Fenabrave, 2010.

GIGLIO, E. M. O comportamento do consumidor. São Paulo: Pioneira Thomson Learning, 2002.

GRECO, E. Patos, gatos e ratos... Estado de Minas, Belo Horizonte, 20 set. 2003. Veículos, p.11.

HAIR JR., J. F. et al. Análise multivariada de dados. Porto Alegre: Bookman, 2009.

KOTLER, P.; KELLER, K. Administração de marketing. São Paulo: Makron Books, 2006.

MALHOTRA, N. K. Pesquisa de marketing: uma orientação aplicada. Porto Alegre: Bookman, 2006.

MARCONI, M. A.; LAKATOS, E. M. Técnicas de pesquisa. São Paulo: Atlas, 2008.

MARTINEZ, E.; POLO, Y.; FLAVIAN, C. The Acceptance and Diffusion of New Consumers Durables: differences between first and last adopters. The Journal of Consumer Marketing. v.15, n. 4, p. 323-341, 1998.

MORAIS, P. de. O tira-teima do sistema flex. Estado de Minas, Belo Horizonte, 9/10/2004. Veículos, p.3.

Pulo do gato faz um ano. Estado de Minas, Belo Horizonte, 27 mar. 2004. Veículos, p.3.

MORGAN, A.; GRIEGO, V. Easy Use and Interpretation of SPSS for Windows: answering research questions with statistics. New Jersey: Lawrence Erlbaum Associates, 1998.

MOWEN, J. C.; MINOR, M. S. Comportamento do consumidor. São Paulo: Prentice Hall, 2003.

NEWTON, R. R.; RUDESTAM, K. E. Your statistical consultant: Answer To Your Research \& Data Analysis Questions. Sage-UK, 1999.

PESTANA, J. N.; GAGEIRO, M. H. Análise de dados para ciências sociais: a complementariedade do SPSS. Lisboa: Sílabo, 2000.

PETER, J. P.; OLSON, J. C. Consumer behavior and marketing strategy. New York: Irwin/McGrawHill, 1999.

SELLTIZ, et al. Métodos de pesquisas nas relações sociais. São Paulo: Pedagógica Universitária, 2005.

SHETH, J. N.; MITTAL, B.; NEWMAN, B. I. Comportamento do Cliente: indo além do comportamento do consumidor. São Paulo: Atlas, 2001.

SOLOMON, M. R. O Comportamento do consumidor: comprando, possuindo e sendo. Porto Alegre: Bookman, 2010.

TABACHINIK, B. G.; FIDELL, L. S. Using multivariate statistics. 4 ed. New York: HarperCollins, 2001. 